\title{
Cone Metric Version of Existence and Convergence for Best Proximity Points
}

\author{
Byung-Soo Lee
}

\author{
Kyungsung University, Busan 608-736, Korea \\ ${ }^{*}$ Corresponding Author: bslee@ks.ac.kr
}

Copyright (C)2014 Horizon Research Publishing All rights reserved.

\begin{abstract}
In 2011, Gabeleh and Akhar [3] introduced semi-cyclic-contraction and considered the existence and convergence results of best proximity points in Banach spaces. In this paper, the author introduces a cone semicyclic $\varphi$-contraction pair in cone metric spaces and considers best proximity points for the pair in cone metric spaces. His results generalize the corresponding results in $[1-5]$.
\end{abstract}

Keywords a cone semi-cyclic $\varphi$-contraction pair, best proximity point, cone metric space, Banach space

2010 Mathematic Subject Classification: 47H10, 54H25

\section{Introduction and Preliminaries}

The existence and the convergence of best proximity points may be very applicable in nonlinear analysis including optimization problems by considering the strong applications of fixed point theory.

A cone metric space is a generalization of a metric space by replacing the real numbers with Banach spaces ordered by the given cone $[4,6]$. Generally, it is not possible to find the exact solution to the equation $T x=x$ for a non-self mapping $T: A \rightarrow B$ defined on a cone metric space $(X, d)$, where $A$ and $B$ are nonempty subsets of $(X, d)$, Hence to focus the study on the problem of finding an element $x$ which is the closest proximity to $T x$ is considerable in optimization senses. To consider a global minimization problem for a mapping $G: A \rightarrow(E, P)$, a Banach space ordered by a given cone $P$, defined by $G(x)=d(x, T x)$ due to the fact that $d(A, B) \leq d(x, T x)$ for all $x \in A$, is very reasonable and interesting.

In 2007, Al-Thagafi and Shahzad [1] introduced a class of cyclic $\varphi$-contractions in metric spaces which contains a class of cyclic contractions as a subclass, introduced by Eldred and Veeramani [2]. They obtained convergence and existence results of best proximity points for a cyclic $\varphi$-contractions in metric spaces and proved the existence of a best proximity point for a cyclic contraction in a reflexive Banach spaces which provide a positive answer to Eldred and Veeramani's question [2].

In 2011, Gabeleh and Akhar [3] introduced semi-cyclic-contraction and considered the existence and convergence results of best proximity points in Banach spaces.

In this paper, we introduce a cone semi-cyclic $\varphi$-contraction pair and obtain the existence and convergence results for the pair in cone metric spaces. Our results generalize the corresponding results in [1-5].

A nonempty subset $P$ of a real Banach space $E$ is called a (pointed) cone if and only if (P1) $P$ is closed, $P \neq\{0\},(\mathrm{P} 2)$ for $a, b \in \mathbb{R}$ with $a, b \geq 0, x, y \in P$ implies $a x+b y \in P$ and (P3) $x \in P$ and $-x \in P$ implies $x=0$.

We define a partial ordering ' $\preceq$ ' with respect to $P$ as follows; for $x, y \in E$, we say that $x \preceq y$ if and only if $y-x \in P, x \ll y$ if and only if $y-x \in$ int $P$, where intP denotes the interior of $P, x \prec y$ if and only if $x \preceq y$ and $x \neq y$. A cone $P$ is said to be normal if there is a number $K>0$ such that for all $x, y \in E, 0 \leq x \leq y$ implies $\|x\| \leq K\|y\|$.

Let $M$ be a nonempty set and $(E, P)$ a Banach space with a given cone $P$. A mapping $d: M \times M \rightarrow(E, P)$ satisfying the conditions $(\mathrm{d} 1) 0 \preceq d(x, y)$ for all $x, y \in M$ and $d(x, y)=0$ if and only if $x=y,(\mathrm{~d} 2) d(x, y)=d(y, x)$ for all $x, y \in M$ and $(\mathrm{d} 3) d(x, y) \preceq d(x, z)+d(y, z)$ for all $x, y, z \in M$ is called a cone metric on $M$ and $(M, d)$ is called a cone metric space.

Definition 1.1. [5]. Let $(M, d)$ be a cone metric space. $A$ subset $A$ of $M$ is said to be bounded above if there exists $c \in \operatorname{int} P$ such that $c-d(x, y) \in P$ for all $x, y \in A$, and is said to be bounded if $\delta(A)=\sup \{d(x, y): x, y, \in A\}$ exists in $E$. 
Let $\left\{x_{n}\right\}$ be a sequence in $(M, d)$ and $x \in(M, d)$. If for every $c \in$ int $P$, there is a natural nember $N$ such that for all $n>N, c-d\left(x_{n}, x\right) \in i n t P$, then we say that $\left\{x_{n}\right\}$ converges to $x$ with respect to $P$ and denote as $\lim _{n \rightarrow \infty} x_{n}=x$.

Lemma 1.1. [4] Let $P$ be a normal cone. Let $\left\{x_{n}\right\}$ and $\left\{y_{n}\right\}$ be sequences in $(M, d)$.

(i) $\left\{x_{n}\right\}$ converges to $x$ with respect to $P$ if and only if $d\left(x_{n}, x\right) \rightarrow 0$ as $n \rightarrow \infty$;

(ii) If $x_{n} \rightarrow x$ and $y_{n} \rightarrow y$ as $n \rightarrow \infty$ with respect to $P$, then $d\left(x_{n}, y_{n}\right) \rightarrow d(x, y)$ as $n \rightarrow \infty$.

(iii) If $x_{n} \rightarrow x$ and $y_{n} \rightarrow y$ as $n \rightarrow \infty$ with respect to $P$ and $y_{n}-x_{n} \in P$ for all $n \in \mathbb{N}$, then $y-x \in P$.

\section{Properties of Constructed Sequences}

Let $A$ and $B$ be nonempty subsets of a cone metric space $(M, d)$ and $S, T: A \cup B \rightarrow A \cup B$ be mappings defined by $S(A \cup B) \subseteq B$ and $T(A \cup B) \subseteq A$.

Definition 2.1. A pair $(S, T)$ is called a cone semi-cyclic $\varphi$-contraction pair if for a strictly increasing mapping $\varphi: E \rightarrow E$,

$$
d(S x, T y) \preceq d(x, y)-\varphi(d(x, y))+\varphi(d(A, B)) \text { for } x \in A \text { and } y \in B .
$$

When $S=T, T$ is called a cone cyclic $\varphi$-contraction, where $d(A, B)=\inf _{\substack{x \in A \\ y \in B}} d(x, y)$.

Example 2.1. Put $(M, d)=\left(\left\{\left(x_{1}, x_{2}\right): x_{1} \geq 0, x_{2} \geq 0\right\},|\cdot|\right) \subset \mathbb{R}^{2}, E=\mathbb{R}$ and $P=(-\infty, 0]$. Let $A=$ $\left\{\left(x_{1}, x_{2}\right) \mid 0 \leq x_{1} \leq 4, x_{2} \geq 4\right\}, B=\left\{\left(x_{1}, x_{2}\right) \mid x_{1} \geq 4,0 \leq x_{2} \leq 4\right\}$ be subsets of $(M, d)$ and $\varphi: \mathbb{R} \rightarrow \mathbb{R}$ be a function defined by $\varphi(t)=t$ for $t \in \mathbb{R}$.

Define mappings $S, T: A \cup B \rightarrow A \cup B$ by

$$
\begin{aligned}
& S\left(x_{1}, x_{2}\right)= \begin{cases}\left(x_{2}, x_{1}\right) & \text { for }\left(x_{1}, x_{2}\right) \in A \\
\left(x_{1}, x_{2}\right) & \text { for }\left(x_{1}, x_{2}\right) \in B,\end{cases} \\
& T\left(x_{1}, x_{2}\right)= \begin{cases}\left(x_{1}, x_{2}\right) & \text { for }\left(x_{1}, x_{2}\right) \in A \\
\left(x_{2}, x_{1}\right) & \text { for }\left(x_{1}, x_{2}\right) \in B,\end{cases}
\end{aligned}
$$

then $S(A \cup B) \subset B$ and $T(A \cup B) \subset A$.

Moreover,

$$
\begin{aligned}
& d(x, y)-\varphi(d(x, y))+\varphi(d(A, B))-d(S x, T y) \\
= & d(x, y)-d(x, y)+0-d(S x, T y) \\
= & -d(S x, T y) \\
\leq & 0 \text { for } x \in A \text { and } y \in B .
\end{aligned}
$$

Hence

which implies that

$$
d(x, y)-\varphi(d(x, y))+\varphi(d(A, B))-d(S x, T y) \in P
$$

$$
d(S x, T y) \preceq d(x, y)+\varphi(d(x, y))+\varphi(d(A, B)) .
$$

Thus $(S, T)$ is a cone semi-cyclic $\varphi$-contraction pair.

Remark 2.1. (i) A cone semi-cyclic k-contraction pair is a cone semi-cyclic $\varphi$-contraction pair with $\varphi(x)=$ $(1-k) x$ for $x \in E$. In this case the pair $(S, T)$ satisfies for some $k \in(0,1)$

$$
d(S x, T y) \preceq k \cdot d(x, y)+(1-k) \cdot d(A, B) \text { for all } x \in A \text { and } y \in B .
$$

(ii) When $S=T, T$ is called a cone cyclic k-contraction.

Sequences Construction For a cone semi-cyclic $\varphi$-contraction pair $(S, T)$, letting $x_{0} \in A, y_{0}=S x_{0} \in B, x_{1}=$ $T y_{0} \in A$ and $y_{1}=S x_{1} \in B$ inductively, we have two sequences $\left\{x_{n}\right\}$ in $A$ and $\left\{y_{n}\right\}$ in $B$ such that

$$
x_{n+1}=T y_{n} \text { and } y_{n}=S x_{n} \text { for } n \in \mathbb{N} \cup\{0\} .
$$

Theorem 2.1. Let $A$ and $B$ be nonempty subsets of a cone metric space $(X, d)$ and $(S, T)$ a cone semi-cyclic $\varphi$-contraction pair.

Then for the sequences $\left\{x_{n}\right\}$ and $\left\{y_{n}\right\}$ generated as (2.1), two new sequences $\left\{d\left(x_{n}, S x_{n}\right)\right\}$ and $\left\{d\left(y_{n+1}, T y_{n}\right)\right\}$ are decreasing and converge to $d(A, B)$ in $E$. 
Proof. For a strictly increasing mapping $\varphi: E \rightarrow E$

$$
\varphi(d(A, B)) \preceq \varphi(d(x, y)) \text { for all } x \in A \text { and } y \in B,
$$

so that

$$
\begin{aligned}
d(S x, T y) & \preceq d(x, y)-\varphi(d(x, y))+\varphi(d(A, B)) \\
& \preceq d(x, y) .
\end{aligned}
$$

Thus we have

$$
\begin{aligned}
d\left(x_{n}, S x_{n}\right) & =d\left(T y_{n-1}, S x_{n}\right) \\
& \preceq d\left(y_{n-1}, x_{n}\right) \\
& =d\left(S x_{n-1}, T y_{n-1}\right) \\
& \preceq d\left(x_{n-1}, y_{n-1}\right) \\
& =d\left(x_{n-1}, S x_{n-1}\right) .
\end{aligned}
$$

Hence the sequence $\left\{d\left(x_{n}, S x_{n}\right)\right\}$ is decreasing in $E$.

Since $\left\{d\left(x_{n}, S x_{n}\right)\right\}$ is bounded below, $\lim _{n \rightarrow \infty} d\left(x_{n}, S x_{n}\right)$ exists.

Put $t_{0}=\lim _{n \rightarrow \infty} d\left(x_{n}, S x_{n}\right)$, then for $c \in i n t P$, there exists a natural number $\mathrm{N}$ such that if $n \geq \mathrm{N}$, then

$$
c-d\left(d\left(x_{n}, S x_{n}\right), t_{0}\right) \in \operatorname{intP} .
$$

If $t_{0}>d(A, B)$, then for $t_{0}-d(A, B) \in P$, there exists $\left(x_{0}, y_{0}\right) \in A \times B$ such that

$$
c-d\left(d\left(x_{n}, S x_{n}\right), t_{0}\right)+d(A, B)-d\left(x_{0}, y_{0}\right) \in P .
$$

Consequently, from (2.2) and (2.3), we have $d(A, B)-d\left(x_{0}, y_{0}\right) \in P \backslash \operatorname{int} P \subset P$, which is a contradiction.

Hence we have $\lim _{n \rightarrow \infty} d\left(x_{n}, S x_{n}\right)=d(A . B)$.

The same method also shows that $\left\{d\left(y_{n+1}, T y_{n}\right)\right\}$ is decreasing and $\lim _{n \rightarrow \infty} d\left(y_{n+1}, T y_{n}\right)=d(A, B)$.

Corollary 2.2. For a sequence $\left\{x_{n}\right\}$ constructed as $x_{n+1}=T x_{n}$ for $x_{0} \in A(n \in \mathbb{N} \cup\{0\})$, where $T: A \cup B \rightarrow A \cup B$ is a cone cyclic $\varphi$-contraction, we have the same result as $d\left(x_{n}, x_{n+1}\right) \downarrow d(A, B)$.

Corollary 2.3. Let $A$ and $B$ be nonempty subsets of a cone metric space $(M, d)$. Let $T: A \cup B \rightarrow A \cup B$ be a cone cyclic $k$-contraction. Then $d\left(x_{n}, x_{n+1}\right)$ converges $d(A, B)$, where $x_{0}$ is a given point of $A$ and $x_{n+1}=T x_{n}(n \in$ $\mathbb{N} \cup\{0\})$.

Proof. Now

$$
\begin{aligned}
d\left(x_{n}, x_{n+1}\right) & \preceq k \cdot d\left(x_{n-1}, x_{n}\right)+(1-k) \cdot d(A, B) \\
& \preceq k \cdot\left(k \cdot d\left(x_{n-2}, x_{n-1}\right)+(1-k) \cdot d(A, B)\right) \\
& =k^{2} \cdot d\left(x_{n-2}, x_{n-1}\right)+\left(1-k^{2}\right) \cdot d(A, B) \\
& \preceq k^{2} \cdot\left(k \cdot d\left(x_{n-3}, x_{n-2}\right)+(1-k) \cdot d(A, B)\right) \\
& =k^{3} \cdot d\left(x_{n-3}, x_{n-2}\right)+\left(1-k^{3}\right) \cdot d(A, B) .
\end{aligned}
$$

Inductively, we have

$$
d\left(x_{n}, x_{n+1}\right) \preceq k^{n} \cdot d\left(x_{0}, x_{1}\right)+\left(1-k^{n}\right) \cdot d(A, B) .
$$

Letting $n \rightarrow \infty$, we have $\lim _{n \rightarrow \infty} d\left(x_{n}, x_{n+1}\right)=d(A, B)$.

We have the corresponding result to Theorem 2.1 as a corollary in metric spaces as follows;

Corollary 2.4. [1]. Let $A$ and $B$ be nonempty subsets of a metric space $X$ and $T: A \cup B \rightarrow A \cup B$ be a cyclic $\varphi$-contraction mapping. For $x_{0} \in A$, define $x_{n+1}=T x_{n}$ for each $n \geq 0$, then $d\left(x_{n}, x_{n+1}\right) \rightarrow d(A, B)$ as $n \rightarrow \infty$. Now we show that the generated sequences $\left\{x_{n}\right\}$ and $\left\{y_{n}\right\}$ in (2.1) are bounded.

Theorem 2.5. Let $A$ and $B$ be nonempty subsets of a normal cone metric space $(X, d)$ and $(S, T)$ be a cone semicyclic $\varphi$-contraction pair. For given point $x_{0} \in A$, the sequences $\left\{x_{n}\right\}$ and $\left\{y_{n}\right\}$ generated as (2.1) are bounded.

Proof. We show that $\left\{x_{n}\right\}$ is bounded. Since $d\left(x_{n}, 0\right) \preceq d\left(x_{n}, S x_{n}\right)+d\left(S x_{n}, 0\right)$ and $\left\{d\left(x_{n}, S x_{n}\right)\right\}$ is bounded, it is enough to show that $\left\{S x_{n}\right\}$ is bounded. For the unbounded mapping $\varphi$, take $M \in E$ such that $\varphi(M) \succ$ $d\left(x_{0}, x_{1}\right)+\varphi(d(A, B))$. If $\left\{S x_{n}\right\}$ is not bounded, then there exists a natural number $N \in \mathbb{N}$ such that

$$
d\left(x_{1}, S x_{N}\right) \succ M \text { and } d\left(x_{1}, S x_{N-1}\right) \preceq M .
$$


Hence by the definition of $(S, T)$,

$$
\begin{aligned}
M \prec d\left(x_{1}, S x_{N}\right) & =d\left(T y_{0}, S x_{N}\right) \\
& \preceq d\left(y_{0}, x_{N}\right) \\
& =d\left(S x_{0}, T y_{N-1}\right) \\
& \preceq d\left(x_{0}, y_{N-1}\right)-\varphi\left(d\left(x_{0}, y_{N-1}\right)\right)+\varphi(d(A, B)) \\
& \preceq d\left(x_{0}, x_{1}\right)+d\left(x_{1}, S x_{N-1}\right)-\varphi\left(d\left(x_{0}, S x_{N-1}\right)\right)+\varphi(d(A, B)) \\
& \preceq d\left(x_{0}, x_{1}\right)+M-\varphi\left(d\left(x_{0}, S x_{N-1}\right)\right)+\varphi(d(A, B)),
\end{aligned}
$$

so,

$$
\varphi\left(d\left(x_{0}, S x_{N-1}\right)\right) \prec d\left(x_{0}, x_{1}\right)+\varphi(d(A, B)) .
$$

On the other hand,

$$
\begin{aligned}
M & \prec d\left(x_{1}, S x_{N}\right) \\
& \preceq d\left(x_{0}, y_{N-1}\right) \\
& =d\left(x_{0}, S x_{N-1}\right) .
\end{aligned}
$$

Consequently, by (2.4) and (2.5)

$$
\varphi(M) \prec \varphi\left(d\left(x_{0}, S x_{N-1}\right)\right) \prec d\left(x_{0}, x_{1}\right)+\varphi(d(A, B)) \prec \varphi(M),
$$

which is a contradiction. Hence $\left\{x_{n}\right\}$ is bounded.

Similarly $\left\{y_{n}\right\}$ is bounded.

\section{Best Proximity Point}

Now we show the best proximation result between two sets $A$ and $B$ in a normal cone metric space $(X, d)$ for a cone semi-cyclic $\varphi$-contraction pair $(S, T)$.

Theorem 3.1. Let $A$ and $B$ be nonempty subsets of a normal cone metric space $(X, d)$ and $(S, T)$ be a cone semi-cyclic $\varphi$-contraction pair. For a given point $x_{0} \in A$, the sequences $\left\{x_{n}\right\}$ in $A$ and $\left\{y_{n}\right\}$ in $B$ generated as $(2.1)$,

(i) if $\left\{y_{n}\right\}$ has a convergent subsequence $\left\{y_{n_{k}}\right\}$ in $B$, then there exists a $y \in B$ such that $d(y, T y)=d(A, B)$. In particular, if $d(A, B)=0$, then the $y$ is unique.

(ii) if $\left\{x_{n}\right\}$ has a convergent subsequence $\left\{x_{n_{k}}\right\}$ in $A$, then there exists a $x \in A$ such that $d(x, S x)=d(A, B)$. In particular, if $d(A, B)=0$, then the $x$ is unique.

Proof. (i) Let $y=\lim _{k \rightarrow \infty} y_{n_{k}}$. Since

$$
\begin{aligned}
d(A, B) & \preceq d\left(T y_{n_{k}}, y\right) \\
& \preceq d\left(T y_{n_{k}}, y_{n_{k+1}}\right)+d\left(y_{n_{k+1}}, y\right),
\end{aligned}
$$

by letting $k \rightarrow \infty$, by Lemma 1.1 and Theorem 2.1 we have

$$
\begin{aligned}
d(A, B) & \preceq \lim _{k \rightarrow \infty} d\left(T y_{n_{k}}, y\right) \\
& \preceq \lim _{k \rightarrow \infty} d\left(T y_{n_{k}}, y_{n_{k+1}}\right)+\lim _{k \rightarrow \infty} d\left(y_{n_{k+1}}, y\right) . \\
& =\lim _{k \rightarrow \infty} d\left(T y_{n_{k}}, y_{n_{k+1}}\right) \\
& =d(A, B) .
\end{aligned}
$$

Hence

$$
\begin{aligned}
d(A, B) & \preceq \lim _{k \rightarrow \infty} d\left(T y_{n_{k}}, y\right) \\
& =d(A, B)
\end{aligned}
$$

Hence

$$
d(A, B)=\lim _{k \rightarrow \infty} d\left(T y_{n_{k}}, y\right)
$$


On the other hand,

$$
\begin{aligned}
d(A, B) & \preceq d\left(T y, y_{n_{k}}\right) \\
& =d\left(T y, S x_{n_{k}}\right) \\
& \preceq d\left(y, x_{n_{k}}\right) \\
& =d\left(y, T y_{n_{k}-1}\right) .
\end{aligned}
$$

Letting $k \rightarrow \infty$ in (3.2), from (3.1),

we have

$$
\begin{aligned}
d(A, B) & \preceq \lim _{k \rightarrow \infty} d\left(T y, y_{n_{k}}\right) \\
& \preceq \lim _{k \rightarrow \infty} d\left(y, T y_{n_{k}-1}\right) \\
& =d(A, B) .
\end{aligned}
$$

Hence by Lemma 1.1,

$$
\begin{aligned}
d(A, B) & =\lim _{k \rightarrow \infty} d\left(T y, y_{n_{k}}\right) \\
& =d(T y, y)
\end{aligned}
$$

On the other hand,

assume that $d(y, T y)=d(A, B), d(z, T z)=d(A, B)$ and $y \neq z$ in $B$.

Since

$$
\begin{aligned}
d(y, z) & \preceq d(y, T y)+d(T y, z) \\
& \preceq d(y, T y)+d(T y, T z)+d(T z, z), \\
d(y, z)-d(T y, T z) & \preceq d(y, T y)+d(T z, z) \\
& =2 d(A, B) \\
& =0,
\end{aligned}
$$

which shows that

$$
\begin{aligned}
d(y, z) & \preceq d(T y, T z) \\
& \preceq d(y, z)-\varphi(d(y, z))+\varphi(d(A, B))
\end{aligned}
$$

Hence

which is a contradiction.

$$
\varphi(0) \prec \varphi(d(y, z)) \preceq \varphi(d(A, B))=\varphi(0),
$$

(ii) It can be proued by the same method.

Remark 3.1. If $A:=\left\{x_{0}\right\}$ is a singleton, then $\left\{x_{n}\right\}_{n \in \mathbb{N}}=\left\{x_{0}\right\}$ and $\left\{y_{n}\right\}_{n \in \mathbb{N}}=\left\{y_{0}\right\}:=\left\{S x_{0}\right\} \in B$. Hence $d\left(x_{0}, y_{0}\right)=d\left(x_{0}, B\right)=\inf _{y \in B} d\left(x_{0}, y\right)$, which shows that $B$ is closed. Similarly $A$ is also closed.

\section{REFERENCES}

[1] M. A. Al-Thagafi and N. Shahzad, Convergence and existence results for best proximity points, Nonlinear Analysis 70 (2009), 3665-3671.

[2] A. A. Eldred and P. Veeramani, Existence and convergence of best proximity points, J. Math. Anal. Appl. 232 (2006), 1001-1006.

[3] M. Gabeleh and A. Abkar, Best proximity points for semi-cyclic contractive pairs in Banach spaces, Int. Math. Forum 6(44) (2011), 2179-2186.

[4] L.G. Huang and X. Zhang, Cone metric spaces and fixed point theorems of contractive mappings, J. Math. Anal. Appl. 332 (2007), 1468-1476

[5] D. Turkoglu, M. Abuloha and T. Abdeljawad, KKM mappings in cone metric spaces and some fixed point theorems, Nonlinear Analysis 72 (2010), 348-353.

[6] V. Zabrejko, K-metric and K-normed spaces: a survey, Collect. Math. 48(4-6) (1997), 825-859. 